\title{
The state of Australian public relations: Professionalisation and paradox
}

\author{
By Nigel M. de Bussy and Katharina Wolf \\ School of Marketing, Curtin University of Technology, Perth
}

\begin{abstract}
It is almost a decade since the last empirical study of Australian public relations appeared in the academic literature. This paper reports on a survey conducted immediately prior to the onset of the global financial crisis aimed at revealing the state of public relations in Australia. In particular, the study investigated levels of professionalisation in terms of such criteria as the strategic orientation of public relations, its position within organisational hierarchies, and the importance placed on ethics and professional development. The findings show Australian PR professionals to be highly educated, comparatively well paid and frequently in positions of influence with their CEOs. Paradoxically despite these strengths, the profession in Australia does not seem to have outgrown public relations' pervasive identity crisis.
\end{abstract}

\section{Introduction}

Over recent years, there has been an upsurge in research on the way public relations is practised in particular countries (e.g., Sriramesh \& Verčič, 2009). In many such studies, the issue of professionalism is a key area of focus (e.g., Gupta, 2007; Niemann-Struweg \& Meintjes, 2008; Zulhamri \& Threadgold, 2008). The last empirical review of Australian public relations to appear in the academic literature was published almost a decade ago, based on data collected in the 1990s (Singh \& Smyth, 2000). Strictly speaking, the subject of Singh and Smyth's (2000) study was a single State rather than Australia as a whole. Their data referred almost exclusively to New South Wales - one of six States and two mainland Territories comprising the Commonwealth of Australia (the official name of the federal nation). At the turn of the century, Singh and Smyth (2000) reported growing levels of professionalisation and increasing acceptance of public relations as a strategic management function. 
It seems timely to update the empirical data on Australian public relations to evaluate changes over the past decade, including the adoption thus far of Web 2.0 technologies, and also to provide a more comprehensive national overview than has been available hitherto. This study is based on data collected in late 2007 and 2008 from some 322 Australian public relations practitioners. The findings provide a snapshot of the profession in Australia immediately prior to the onset of the global financial crisis. It was a time of rapid economic growth and high demand for the services of PR professionals. In the words of one respondent, "There appears to be a skills shortage. Experienced people I know in the industry are getting poached left, right and centre". Paradoxically, participants reported that public relations continues to be poorly regarded, despite appearing to meet a number of key benchmarks relating to professionalisation.

\section{Criteria for professionalism}

Two main approaches to conceptualising professionalism in public relations are evident in prior research. Some authors take a broadly social scientific perspective (e.g., L'Etang, 1999; Niemann-Struweg \& Meintjes, 2008). Drawing on sociological literature, L'Etang (1999) identified a number of key traits possessed by professions. These include the development of a 'domain of expertise'; the ability to exercise a monopoly in the provision of services based on that expertise and limit entry to the field; high social status; the acceptance of fiduciary responsibilities towards clients; a code of ethics; and, education as a means of testing competence and maintaining standards. Wylie (1994) stressed a well-defined body of knowledge; standardised educational courses; examination and certification; and, oversight by a body with sufficient authority to exercise disciplinary powers over practitioners. Wylie (1994) claimed public relations met only the first of these four criteria.

In contrast, other authors have equated professionalism with the roles undertaken by public relations practitioners (Karadjov, Kim, \& Karavasilev, 2000; Kim \& Hon, 1998; Wu \& Taylor, 2003). Specifically, studies using this approach have defined professionalism in terms of 'professional' versus 'craft' modes of practice based on the four models of public relations (Grunig \& Hunt, 1984). In these studies, the existence of 'professional' public relations is evidenced by the use of the two-way 
symmetric and two-way asymmetric models in the country in question. 'Craft' public relations is said to be exemplified by reliance on the press agent/publicity and public information models.

In developing a battery of items to measure professionalism in public relations, Cameron, Sallot and Weaver Lariscy (1996) combined elements of both approaches. Their instrument has been used in a number of subsequent studies (Gupta, 2007; Sallot, Cameron, \& Weaver Lariscy, 1997, 1998). Using factor analysis, Cameron et al. (1996) identified several dimension of professionalism including skills and activities; salary levels; use of research; the role of public relations within the organisation; ethics; racial and gender equity; accreditation and licensing; and, education.

In common with most other nations, Australia does not have a system of licensing for public relations practitioners and there are few barriers to entry. Hence, using sociological criteria (L'Etang, 1999) public relations clearly does not qualify as a profession in Australia. However, if professionalism is defined in terms of the role of public relations a different picture emerges. Therefore, this study focuses on factors such as the strategic orientation of public relations, its position within organisational hierarchies, and the importance placed on ethics and professional development.

\section{Methodology}

The data were collected using an online questionnaire which was available for completion from late-2007 until mid-2008. To encourage responses information about the survey, including a web link, was posted in all State, Territory and national ezines produced by the Public Relations Institute of Australia (PRIA). The invitation to participate was also sent via email to the researchers' professional contacts. Reminders were sent out periodically during the period the survey was open. A snowball sampling strategy was adopted. Participants were encouraged to forward the survey to their professional colleagues, who were in turn invited to pass on the details to their contacts and so on. The survey began with a filter question asking respondents if they believe they work primarily in a public relations role - no matter what their actual job title may be. Those responding in the negative exited the survey. 
The advantage of snowball sampling is that it maximises the number of responses by enabling the survey to reach potential respondents who may not have been directly accessible to the researchers (Salganik \& Heckathorn, 2004). The disadvantage is that the representativeness of the resultant sample may be compromised. In a snowball sample, it is not the case that each member of the population of interest has an equal probability of being selected. The total number of responses received (322) compares favourably with similar recent surveys undertaken in other countries (e.g., Gupta, 2007; Niemann-Struweg \& Meintjes, 2008; Wu \& Taylor, 2003). Despite the prominent role of PRIA channels of communication in 'seeding' the survey, there was an almost equal split of PRIA members (53.7\%) and non-members (46.3\%) in the final sample. This suggests that the survey successfully engaged many practitioners unreachable via the Institute's mailing list. Nevertheless, the composition of the sample is carefully analysed in the following section and the implications for the generalisability of the results are discussed.

This paper discusses the results of six of the survey's sections: demographic questions about the respondents and their organisations; research and evaluation; the position of public relations within the organisation; practitioners' daily activities; ethics and professional development; and, the use of social media. The items were based largely on a pilot study conducted in Western Australia in 2001. Apart from the purely demographic questions, the majority of items used five-point Likert-type scales anchored by 'strongly disagree' and 'strongly agree'. An additional section invited open-ended comments on the state of public relations in Australia and perceptions of the PRIA. The qualitative findings focusing mainly on the PRIA have been reported in a separate paper (Wolf \& de Bussy, 2008). All quantitative data were analysed using SPSS 15.

\section{Findings}

\subsection{Demographics}

A decade ago, Singh \& Smyth (2000) noted the growing feminisation of public relations in Australia. In the survey they reported on, $61 \%$ of respondents were female 
and $39 \%$ male. However, the males were concentrated in what was then the over-40 age cohort. It is therefore unsurprising that the passage of time has resulted in an even greater preponderance of female practitioners. In the current study, $79.2 \%$ of respondents were women and $19.8 \%$ men. Only in the over-60 age bracket were men in the majority. Practitioners in the middle years of their working life formed the largest group of respondents with $45.9 \%$ aged $30-49$. Younger practitioners (under 30 years) were also well represented (43.2\%) with those aged over 50 accounting for $10.8 \%$ of the sample.

Some $90.7 \%$ of respondents hold a tertiary degree - of those $42.12 \%$ have attained postgraduate qualifications or higher degrees. Public relations was the principal subject of study for $42.1 \%$ of graduates, $16.4 \%$ specialised in communication, $10.9 \%$ in journalism or media, $6.3 \%$ in marketing, and $9.5 \%$ in other business subjects. The choice of subject studied at university is markedly age related. Of those majoring in public relations, $81.25 \%$ are aged under 35 . These PR degree holders represent $57.77 \%$ of all practitioners in their age cohort. In contrast, only $18.68 \%$ of practitioners aged over 40 hold a degree specifically in public relations. These statistics reflect both the relatively recent widespread availability of tertiary public relations courses in Australia and the extent to which PR-specific qualifications have become the preferred mode of entry into the profession since their inception. Some $56.4 \%$ of respondents agreed their organisation considers holding a PR degree or equivalent qualification an essential criterion when hiring a PR officer or consultant.

All sectors of the public relations workplace are well represented in the sample with $33.8 \%$ of respondents working in consultancies, $29.4 \%$ in government, $14.4 \%$ in corporations, $14.4 \%$ in non-profits, and $8.1 \%$ employed in other types of organisation. In terms of its representativeness, the sole apparent weakness in the sample is the proportion of respondents from each State. Western Australia (WA) is over represented (44.1\%). Using population and PRIA membership statistics as a guide, WA should account for only about $10 \%$ of the sample. This outcome is no doubt a result of the fact that the researchers are based in WA, combined with the sampling strategy adopted. With some caveats, the other States and Territories are represented in approximate proportion to their size: New South Wales (19.3\%), Victoria (14.6\%), Queensland (8.4\%), South Australia (7.5\%), and the Australian Capital Territory 
(ACT) (5\%). Only two responses were received from each of the Northern Territory and Tasmania. The ACT is disproportionately represented relative to its small population but, as the location of the nation's capital, is the base of much government sector public relations activity.

To evaluate the potential impact of disproportionate State representation, a series of one-way ANOVA tests was conducted to determine if the mean scores for the items measured using Likert scales differed by State. Of 44 items tested, only eight $(18.18 \%)$ produced $p$ values $\leq .05$. Five of these items referred to daily activities conducted by practitioners. For example, Western Australia, New South Wales and Queensland reported somewhat higher than average involvement in social media. The reverse was true for Victoria and the Australian Capital Territory. The reasons for such differences are unclear and appear to have little practical, as opposed to statistical, significance. The remaining three items referred to dimensions also measured by other items which produced non-significant $p$ values. Hence the overrepresentation of Western Australia does not appear to preclude drawing conclusions about professionalism in Australia as a whole from this sample.

\subsection{Salaries}

The modal respondent salary was AU\$60-79,000 per annum (27\%). Almost as many (26.1\%) reported earning between AU\$40-59,000. Some 14\% earned AU\$80$\$ 99,000$, with $23.8 \%$ earning more than AU $\$ 100,000$. At the top end of the salary range, $4.9 \%$ earned more than AU\$160,000. Respondents worked a mean of 42.23 hours per week but with a considerable degree of variation ( $\mathrm{SD}=11.18$ hours). Unsurprisingly, age and salary level are closely related. Some $86.79 \%$ of those aged under 25 earned less than AU\$60,000. In the 25-29 age range, 80.23\% earned AU\$4079,000 , with $11.63 \%$ of this cohort commanding salaries of AU\$80-99,000. Some $24.07 \%$ of $30-34$ year-olds earned more than AU\$100,000, whereas in the over-35 age cohort this figure rises to $44.19 \%$.

Predictably, higher earners tend to work in the commercial sector. Those earning AU $\$ 100,000$ or more represented $30.56 \%$ of consultancy respondents and $32.61 \%$ of those working for corporations. In contrast, only $15.96 \%$ of government sector 
employees and $15.22 \%$ of those working for non-profit organisations reported salaries above AU\$100,000. However, the proportion of those employed by consultancies earning less than AU\$40,000 (10.19\%) was far higher than in corporations (4.35\%) and government (1.06\%). Indeed the figure for non-profit organisations (10.87\%) was only marginally greater. This supports anecdotal evidence that consultancies tend to hire fresh graduates on relatively low salaries, but offer more attractive remuneration at a later stage to employees with a proven track record. A chi-square analysis to determine if there is a relationship between salary and State produced a nonsignificant result.

As a comparison, figures dating from May 2006 (the most recent available) show that $19.1 \%$ of all those classified by the Australian Bureau of Statistics as 'managers', and $7.1 \%$ of those deemed 'professionals', earned more than $\$ 2,000$ per week at that time. Average earnings were AU\$7,402 and AU\$58,505 for managers and professionals respectively (Australian Bureau of Statistics, 2006). However, there continue to be marked disparities in earnings between men and women in Australia. The figures quoted above are for all persons. Among women, only $8.9 \%$ of managers and just $2.5 \%$ of professionals earned more than AU $\$ 2,000$ per week in 2006. Female average annual earnings were AU\$61,859 and AU\$50,658 for managers and professionals respectively (Australian Bureau of Statistics, 2006). Given that almost $80 \%$ of PR practitioners who participated in this study were women, their reported salaries look attractive in comparison.

\subsection{Daily activities}

Respondents were asked to what extent they agreed that particular duties and responsibilities are prominent in their daily activities. Table 1 summarises the results on a scale of $1-5$, where 1 means strongly disagree and 5 means strongly agree. 


\section{Table 1}

Prominence of particular duties and responsibilities in respondents' daily activities

\begin{tabular}{lll}
\hline Activity & Mean & SD \\
\hline Writing and editing & 4.34 & 0.98 \\
Strategic planning and counsel & 3.92 & 1.07 \\
Media relations & 3.86 & 1.28 \\
Internal communications & 3.69 & 1.26 \\
Marketing communication & 3.46 & 1.30 \\
Issues and crisis management & 3.45 & 1.31 \\
Research & 3.13 & 1.19 \\
Community relations & 3.13 & 1.32 \\
Print production & 3.13 & 1.33 \\
Event organisation & 3.04 & 1.29 \\
Social media & 2.86 & 1.23 \\
Website maintenance & 2.78 & 1.40 \\
Website development & 2.51 & 1.28 \\
Government lobbying & 2.29 & 1.40 \\
Investor and financial relations & 2.04 & 1.27
\end{tabular}

These results indicate that the traditional public relations activities of writing, editing, media relations and providing strategic communication counsel remain prominent.

Government lobbying and investor and financial relations appear to be niche services performed by a small number of specialists. The relatively low prominence of online activities in practitioners' daily work is somewhat surprising. Crucially, mean values of less than 3 fall below the mid-point for the scale, indicating respondents on average positively disagreed that these duties were prominent in their daily activities. Print production remains a more important daily activity for Australian PR practitioners than website maintenance or social media.

Despite the hype, web 2.0 appears to be an extremely low priority for Australian public relations. Familiarity is not the issue for the majority of practitioners.

Respondents were asked to what extent they were familiar with 11 different web 2.0 technologies including blogs, podcasts, wikis, social networking and video sharing. On a scale of 1-5 where 1 signifies not at all familiar and 5 very familiar, the overall mean for the 11 items was $3.50(\mathrm{SD}=1.22)$. Only in the cases of two technologies was the mean below the mid-point of the scale: Second Life $(M=2.37)$ and photo sharing (e.g. Flickr) $(M=2.95)$. Respondents were then asked how extensively they were embracing each of the 11 technologies as part of their professional communication efforts, from not at all (1) to very extensively (5). The overall mean 
score was $1.89(\mathrm{SD}=1.19)$. Not one of the 11 technologies achieved a mean score above the mid-point of the scale. When asked about the main barriers to the use of web 2.0 in their work, the modal reason provided was 'not considered relevant to target stakeholder(s)' (mentioned by $39.6 \%$ of respondents). The next most commonly cited reasons were 'lack of familiarity' (31.0\%), 'lack of training' (25.4\%), 'lack of time' (24.6\%), 'budget restraints' $(18.2 \%)$, and 'fear of criticism or negative feedback voiced via social media' $(15.5 \%)$.

\subsection{Professionalism}

The perceived extent of professionalism in Australian public relations was evaluated by a battery of 17 items. Unlike the questions relating to practitioners' individual work patterns, these items refer to the respondents' organisations (or client organisations). Principal components factor analysis using the eigenvalues greater than one rule with Varimax rotation was performed on the 17 items, resulting in a four-factor solution accounting for $66.49 \%$ of the total variance. The list of items retained at the end of the analysis is provided in the appendix.

Factor 1 refers to the position of PR within the organisation, the involvement of the $\mathrm{CEO}$ and the working relationship between the CEO and the senior PR manager or consultant. The six items loading onto this factor were subject to scale reliability analysis yielding an alpha coefficient of .90 . Factor 2 reflects the use of research. The alpha score for the five research items is .86. Factor 3 (three items) relates to ethics and professional development $($ alpha $=.68)$. Three items referring to strategic planning loaded onto Factor 4. However, one item was subsequently dropped because of a low item-to-total correlation. The alpha coefficient for the remaining two items is .62. Although alpha reliabilities of .7 or higher are preferable, scales with coefficients as low as .6 may still be regarded as acceptable for exploratory purposes (Nunnally, 1978).

Composite variables were created for each factor by summing the values of the relevant items and then dividing by the number of items to preserve the five-point format. Since 3 represents the mid-point of each scale, a value $\geq 4$ signifies a respondent's agreement that the behaviours captured by each dimension are 
applicable to her organisation. Similarly a score $<3$ indicates disagreement with this proposition. Table 2 shows the level of agreement in relation to each dimension of professionalism.

\section{Table 2}

Respondents' perceptions of professionalism within their organisations

\begin{tabular}{llll}
\hline Dimension & $\begin{array}{l}\text { Agree } \\
\text { (\%) }\end{array}$ & $\begin{array}{l}\text { Neither agree nor } \\
\text { disagree (\%) }\end{array}$ & $\begin{array}{l}\text { Disagree } \\
\text { (\%) }\end{array}$ \\
\hline CEO/PR relationship & 48.4 & 30.8 & 20.8 \\
$\begin{array}{l}\text { Quality of strategic planning } \\
\text { Ethics and professional }\end{array}$ & 38.6 & 35.8 & 25.6 \\
$\begin{array}{l}\text { development } \\
\text { Use of research }\end{array}$ & 36.5 & 37.5 & 26 \\
& 21.5 & 35.6 & 42.9
\end{tabular}

Inevitably, making judgements about the level of agreement required to signify professionalism across the field as a whole is a subjective process. Nevertheless, the fact that the senior PR practitioner provides valued and direct advice on a regular basis to the $\mathrm{CEO}$ in almost half the organisations sampled provides grounds for encouragement. On 'quality of strategic planning' and 'ethics and professional development', more respondents were in agreement than disagreement. However, the figures for the use of formal research suggest room for improvement.

\section{Discussion}

The typical Australian public relations practitioner is female, highly educated, comparatively well-paid, and (for those who have achieved seniority) likely to be a close and trusted confidante of her CEO. There is no, or at least there should not be, any mystery about what public relations practitioners do. Notwithstanding the maddening inability of PR specialists to agree on a definition of their field, the list of duties and responsibilities provided in Table 1 captures a widely accepted and distinctive set of activities associated with the practice of public relations. The contents of this list (at least for those items with mean scores $\geq 3$ ) would not have changed significantly for many years, if not decades. By virtue of answering the filter question discussed above in the affirmative, all 322 respondents self-identified as working primarily in public relations. More than half of respondents have further expressed their professional identity by becoming members of the Public Relations 
Institute of Australia. Yet, only 67 respondents (20.8\%) said the words 'public relations', 'PR', or 'public affairs' were part of their job title.

In the words of one respondent, “Anyone who lists their occupation as 'PR' is either good at throwing a party or making a splash in the social [celebrity/gossip] pages of a Sunday paper". Another wrote, "There is still a strong perception we are all 'spin doctors', and that it is a job anyone can do without training". Paradoxically, it seems the more public relations becomes indispensible to the strategic management of major private and public sector organisations, the more reluctant practitioners become to use the term itself. Despite the positions of influence and comparatively high salaries, PR practitioners appear almost embarrassed to acknowledge their field of practice. Public relations, it may be said, is the profession that dare not speak its name.

\section{Conclusion}

This study provides a snapshot of the public relations profession in Australia in 2008 on the eve of the global financial crisis. Although the snowball sampling strategy adopted has some limitations, it did result in responses from 149 non-PRIA members who would otherwise have been difficult to identify and appears to be an approach worth retaining. In future studies, refinement of some of the measures to further increase scale reliability could be undertaken. Future researchers should consider readministering the survey on a regular basis. It would be particularly interesting to understand the effects of changing economic circumstances on the practice of public relations in Australia and to probe attitudes to web 2.0 technologies in more depth.

\section{References}

Australian Bureau of Statistics. (2006). Employee earnings and hours (No. 6306.0). Canberra, ACT: Author.

Cameron, G. T., Sallot, L. M., \& Weaver Lariscy, R. A. (1996). Developing standards of professional performance in public relations. Public Relations Review, 22(1), 43-61.

Grunig, J. E., \& Hunt, T. (1984). Managing public relations. New York, NY: Holt, Rinehart and Winston. 
Gupta, S. (2007). Professionalism in Indian public relations and corporate communications: An empirical analysis. Public Relations Review, 33(3), 306312.

Karadjov, C., Kim, Y., \& Karavasilev, L. (2000). Models of public relations in Bulgaria and job satisfaction among its practitioners. Public Relations Review, 26(2), 209-218.

Kim, Y., \& Hon, L. C. (1998). Craft and professional models of public relations and their relation to job satisfaction among Korean public relations practitioners. Journal of Public Relations Research, 10(3), 155-175.

L'Etang, J. (1999). Public relations education in Britain: An historical review in the context of professionalisation. Public Relations Review, 25(3), 261-289.

Niemann-Struweg, I., \& Meintjes, C. (2008). The professionalism debate in South African public relations. Public Relations Review, 34(3), 224-229.

Nunnally, J. (1978). Psychometric theory (2nd ed.). New York, NY: McGraw-Hill.

Salganik, M. J., \& Heckathorn, D. D. (2004). Sampling and estimation in hidden populations using respondent-driven sampling. Sociological Methodology, 34(1), 193-240.

Sallot, L. M., Cameron, G. T., \& Weaver Lariscy, R. A. (1997). Professional standards in public relations: A survey of educators. Public Relations Review, 23(3), 197-216.

Sallot, L. M., Cameron, G. T., \& Weaver Lariscy, R. A. (1998). Pluralistic ignorance and professional standards: Underestimating professionalism of our peers in public relations. Public Relations Review, 24(1), 1-19.

Singh, R., \& Smyth, R. (2000). Australian public relations: Status at the turn of the 21st century. Public Relations Review, 26(4), 387-401.

Sriramesh, K., \& Verčič, D. (Eds.). (2009). The global public relations handbook: Theory, research, and practice (Revised ed.). New York, NY: Routledge.

Wolf, K., \& de Bussy, N. M. (2008). Perceptions of professionalism: Practitioner reflections on the state of Australian public relations. Asia Pacific Public Relations Journal, 9, 1-15.

Wu, M.-Y., \& Taylor, M. (2003). Public relations in Taiwan: Roles, professionalism and relationship to marketing. Public Relations Review, 29(4), 473-483.

Wylie, F. W. (1994). Commentary: Public relations is not yet a profession. Public Relations Review, 20(1), 1-3. 
Zulhamri, A., \& Threadgold, T. (2008). Towards the professionalisation of public relations in Malaysia: Perception management and strategy development. Public Relations Review, 34(3), 285-287.

\section{Appendix}

Items in the professionalism scale

CEO/PR relationship $(\alpha=.90)$

1. Our CEO (or client CEO) meets regularly with the senior PR manager or consultant

2. PR research findings are regularly reported to our CEO (or client CEO)

3. Our CEO (or client CEO) regularly receives advice from the senior PR manager or consultant on current issues

4. Our CEO (or client CEO) regularly seeks advice from the senior PR manager or consultant on current issues

5. Our CEO (or client CEO) regularly receives advice from the senior PR manager or consultant on emerging trends in the environment

6. Our CEO (or client CEO) regularly seeks advice from the senior PR manager or consultant on emerging trends in the environment

Quality of strategic planning $(\alpha=.62)$

1. The written communication plans prepared for my organisation or clients always refer to Key Performance Indicators (KPIs) - for example, stakeholder satisfaction levels

2. Feedback received from stakeholders of my organisation or clients is always used to improve operations and policies

Ethics and professional development $(\alpha=.68)$

1. A budget allowance is always made for the education and professional development of public relations employees in my organisation

2. This organisation uses a written Code of Ethics with which all PR activities must comply

3. The senior PR manager or consultant regularly helps the CEO (or client CEO) to do 'the right thing' - even if it costs money 
Use of research $(\alpha=.86)$

1. An allowance is always made for research activities in the public relations budgets prepared for my organisation or clients

2. Research was conducted in the last 12 months to gauge the opinions of stakeholders relevant to my organisation or clients

3. Research was conducted in the last 12 months to set clear and measurable PR objectives relevant to my organisation or clients

4. Research was conducted in the last 12 months to monitor the progress of communication programs relevant to my organisation or clients

5. Research was conducted in the last 12 months to determine if communication objectives relevant to my organisation or clients had been achieved 